\title{
Workshop Entrepreneurship Training For Students At Smk Karsa Mulya Palangka Raya
}

\section{Pelatihan Kewirausahaan Bengkel Bagi Siswa Di Smk Karsa Mulya Palangka Raya}

\author{
Sanggam Roy I. Manalu ${ }^{1)}$ Whendy Trissan ${ }^{2)}$ \\ 1), Program Studi Pendidikan Teknik Mesin, FKIP, UPR \\ 2), Program Studi Pendidikan Teknik Bangunan, FKIP, UPR \\ Kampus Unpar Tunjung Nyaho, Jl. H. Timang, 73111A
}

\begin{abstract}
The creative economic development in city of Palangka Raya is really needed to deal with the challenges of economic growth that is relatively constant or even low after economic crises. High levels of poverty, unemployment and low industrial competitiveness to determine the direction of creative economic development for fulfilling instructions President Number 6 year 2009 is required efforts to develop the Creative Economy Entrepreneurship in the Framework of Enhancing Creative Economic Enterprises in the city of Palangka Raya. The purpose of this ibm is to increase student interest in entrepreneurship and to improve the economy quality and standard of living in the workshop area. Through this ibm activity will be offered a solution to the problems that have been formulated above. The approach is consisting of 1) Preparation Phase, 2) Assessment Phase, 3) Stage Alternative Planning of Programs or Activities, 4) Formulation of Action Plans Phase, 5) Implementation Stage, 6) Evaluation Phase, and 7) Termination Phase. The implementation of the IBM program is indeed carried out as an effort to empower in the field of entrepreneurship through entrepreneurship training activities that focus on business development program. Implementation methods using information technology and social media that will be carried out are (1) business management plate, (2) Production training, (3) administration, and (4) mentoring. All of these methods are an integral part of this IBM program. Workshop entrepreneurship training for vocational schools (mechanical and automotive major) is important to do in preparing students to enter the workforce after completing their education.
\end{abstract}

Keywords: Entrepreneurship Development, Workshop, Creative Economy

\begin{abstract}
ABSTRAK
Pengembangan ekonoml kreatlf di Kota Palangka Raya sangat diperlukan untuk menjawab tantangan permasalahan pembangunan diantaranya pertumbuhan ekonoml yang relatif konstan atau bahkan cenderung rendah pasca krisls ekonomi. Tingkat kemiskiman dan pengangguran yang masih tinggal dan daya saing industri yang masih rendah untuk menentukan arah pengembangan ekonomi kreatif sekaligus memenuhi instruksi Presiden Nomor 6 tahun 2009 diperlukan upaya untuk Pengembangan Kewirausahaan Pelaku Ekonomi Kreatif dalam Rangka Peningkatan Usaha Ekonomi Kreatif di Kota Palangka Raya. Tujuan ibm ini adalah untuk meningkatkan minat siswa dalam berwirausaha dan meningkatkan perekonomian dan taraf hidup di bidang perbengkelan. Dengan melalui kegiatan ibm ini akan ditawarkan solusi bagi permasalahan yang telah dirumuskan di atas. Pendekatan yang ditawarkan bagi sebagai berikut 1) Tahap Persiapan 2) Tahap Assesment 3) Tahap Perencanaan Altematif Program atau Kegiatan 4) Tahap Pemformulasian Rencana Aksi 5) Tahap Pelaksanaan (Implementasi Program atau Kegiatan 6) Tahap Evaluasi serta 7) Tahap Terminasi. Pelaksanaan program ibm ini memang dilaksanakan sebagai upaya pemberdayaan dalam bidang kewirausahaan melalui kegiatan pelatihan kewirausahaan yang menitikberatkan kepada pengembangan usaha. Metode pelaksanaan program dengan menggunakan teknologi informasi dan media sosial yang akan dilakukan adalah (1) pelatihan manajemen usaha, (2) Pelatihan produksl (3) pelatlhan administrasi dan (4) Pendampingan Semua metode ini merupakan satu kesatuan dan program ibm ini. Pelatihan kewirausahaan bengkel bagi SMK khususnya jurusan mesin dan otomotif sangat baik untuk dilakukan untuk mempersiapkan mereka para siswa memasuki dunia kerja setelah menyelesaikan pendidikan.
\end{abstract}

Kata Kunci: Pengembangan Kewirausahaan, Bengkel, Ekonomi Kreatif

\section{PENDAHULUAN}

Pengembangan ekonomi kreatif di Kota Palangka Raya sangat diperlukan untuk menjawab tantangan permasalahan pembangunan, diantaranya pertumbuhan ekonomi yang relatif konstan atau bahkan cenderung rendah pasca krisis ekonomi, tingkat kemiskinan dan pengangguran yang masih tinggi, dan daya saing industri yang masih rendah. Untuk menentukan arah 
pengembangan ekonomi kreatii sekaligus memenuhi Instruksi Presiders Nomor 6 tahun 2009, diperlukan upaya untuk Pengembangan Kewirausahaan Pelaku Ekonomi Kreatif dalam Rangka Peningkatan Usaha Ekonomi di Kota Palangka Raya.

Pelaku ekonomi kreatif bisa dilakukan dalam berbagai bidang usaha, salah satunya adalah bengkel. Bengkel atau workshop adalah sebuah bangunan yang menyediakan ruang dan peralatanuntuk melakukan konstruksi atau manufaktur, dan memperbaiki benda. Sedangkan perbengkelan adalah pengetahuan dan keterampilan tentang peralatan dan metode untuk membuat, membentuk, mengubah bentuk, merakit, ataupun memperbaiki suatu benda menjadi bentuk yang baru atau kondisi yang lebih baik secara manfaat maupun estetika. Perbengkelan merupakan sebuah ilmu yang telah berkembang bahkan sebelum Revolusi Industri karena bengkel merupakan satu-satunya tempat untuk membuat alat hingga berkembangnya industri manufaktur besar Sekolah Menengah Kejuruan merupakan suatu pendidikan menengah formal yang menfokuskan pendidikan pada bidang ilmu kejuruan. Dengan harapan mahasiswa yang lulus dari sekolah tersebut siap memasuki dunia wirausaha dengan bekal pengetahun yang telah didapat. Pendidikan kejuruan menurut Undang-Undang Negara RepublikIndonesia No. 20 Tahun 2003 tentang Sistem Pendidikan Nasional pasal 18 dijelaskan bahwa: "Pendidikan Kejuruan merupakan pendidikan menengah yang mempersiapkan peserta didik terutama untuk bekerja pada bidang tertentu". Sebagai tindak lanjut dari implementasi undang -undang di atas, maka perlu dikembangkan suatu bentuk pendidikankejuruan. Khususnya Sekolah Menengah Kejuruan (SMK) menurut Depdiknas bertujuan untuk:

1). Menyiapkan siswa-siswi untuk memasuki lapangan pekerjaan Serta mengembangkan sikap professional.

2). Menyiapkan siswa agar mampu memilih karir, mampu berkompetisi,dan mampu mengembangkan diri.

Salah satu sekolah menengah kejuruan di kota Palangka Raya adalah SMK Karsa Mulya yang menfokuskan pada kejuruan otomotif atau permesinan.

Kewirausahaan merupakan sikap mental dan jiwa yang selalu aktii kreatif, berdaya saing, bercipta, berkarsa dan bersahaja dalam berusaha dalam rangka meningkatkan pendapatan dalam kegiatan usahanya atau kiprahnya. Seseorang yang memiliki jiwa dan sikap wirausaha selalu tidak puas dengan apa yang telah dicapainya.

\section{Permasalahan Mitra}

Permasalahan yang dialami oleh mantra dalam ini siwa SMK Karsa Mulya adalah kurangnya minat berwirausaha, kurangnya pemahaman tentang manajemen usaha yang kurangnya pengetahuan dan pelatihan kewirausahaan, sehingga dengan adanya kegiatan Pengabdian IbM ini dapat meningkatkan minat kewirausahaan siswa dibidang perbengkelan.

\section{SOLUSI YANG DITAWARKAN}

Dalam kegiatan pengabadian berupa Iptek Bagi Masyarakat ini, pengusul mencoba untuk memberikan solusi bagi kedua mitra SMK Karsa Mulya berupa pemanfaatan Iptek sebagai media informasi dan media sosial dengan tujuan sebagai berikut :

1. Meningkatkan kemampuan dibidang perbengkelan misalnya bongkar pasang spare part dan mesin, memperbaiki kerusakan mesin kendaraan, dan membuat bahan-bahan yang diperlukan dalam merenovasi dan modifikasi kendaraan.

2. Meningkatkatnya motivasi berwirausaha mitra baik secara individu maupun secara kelompok;

3. Meningkatnya pemahaman tentang manajemen usaha terutama yang berkaitan dengan optimalisasi manajemen sumber daya manusia.

4. Memiliki pengetahuan tentang model pembagian tugas dan kewenangan dalam menjalankan usaha bisnis.

5. Meningkatnya pemahaman tentang rumusan dan manfaat perencanaan bisnis (bussines plan) serta dihasilkan dokumen perencanaan bisnis sebagai rencana pengembangan usaha baik dalam jangka pendek, jangka menengah dan jangka panjang.

6. Meningkatnya keterampilan anggota dalam menggunakan kemputer terutama dalam memanfaatkan sofiware-software untuk keperluan desain kreatif serta penggunaan internet untuk media promosi.

7. Meningkatnya pemahaman dan keterampilan dalam membuat media promosi dan strategi pemasaran. Dihasilkan model media promosi baik cetak maupun media di internet.

\section{METODE PELAKSANAAN}

Melalui kegiatan Pelatihan ini akan ditawarkan solusi bagi permasalahan- permasalahan yang telah dirumuskan di atas. Pendekatan yang ditawarkan bagi realisasi program Pelatihan ini adalah model pemberdayaan dengan langkah-langkah sebagai berikut :

1) Tahap Persiapan;

2) Tahap Assesment;

3) Tahap Perencanaan Altematif Program atau Kegiatan;

4) Tahap Pemformulasian Rencana Aksi;

5) Tahap Pelaksanaan (Implernentasz) Program atau Kegiatan;

6) Tahap Evaluasi; Serta

7) Tahap Terminasi.

Pelaksanaan program Pelatihan ini memang dilaksanakan sebagai upaya pemberdayaan dalam bidang kewirausahaan melalui kegiatan pelatihan kewirausahaan 
yang menitikberatkan kepada pengembangan usaha. Metode pelaksanaan program dengan menggunakan teknologi informasi dan media social yang akan dilakukan adalah :

(1) Pelatihan manajemen usaha,

(2) Pelatihan produksi,

(3) Pelatihan administrasi dan

(4) Pendampingan. Semua metode ini merupakan satu kesatuan dari program Pelatihan ini.

\section{PELAKSANAAN KEGIATAN}

Tahap awal kegiatan yaitu melakukan koordinasi dengan pihan sekolah SMK Karsa Mulya tentang jadwal pelaksanaan pelatihan, jumlah siswa peserta pelatihan dan lokasi kegiatan. Tim dari Universitas Palangka Raya juga mempersiapkan semua keperluan baik itu spanduk, konsumsi, dokumentasi dan administrasi. Kegiatan pelatihan dilaksanakan di Aula dan bengkel SMK Karsa Mulya Palangka Raya

Tujuan:

1. Mahasiswa dapat merencanakan penyelanggaraan bengkel
2. Mahasiswa dapat mengelola bengkel

3. Mahasiswa dapat mengembangkan bengkel

\section{Pengantar:}

Salah satu strategi dasar pembangunan pendidikan adalah peningkatan mutu pendidikan, dan salah satu upaya untuk mencapai mutu yang baik diperlukan strategi perencanaan, pengelolaan, dan pengembangan bengkel yang bermutu pula. Untuk melakukan langkah-langkah strategi di atas, harus mempertimbangkan dan melibatkan baik secaxa langsung maupun tidak langsung unsur-unsur terkait, antara lain:

1. Unsur pengelola (institusi)

2. Unsur pelaku (peserta praktik)

3. Unsur pengguna (masyarakat)

4. Unsur pendukung (Pemerintah/orang tua)

\section{Manajemen Bengkel Sebagai Proses Linier}

Masukan Input > Proses $>$ Keluaran Out put > Umpan balik $>$ Masyarakat.

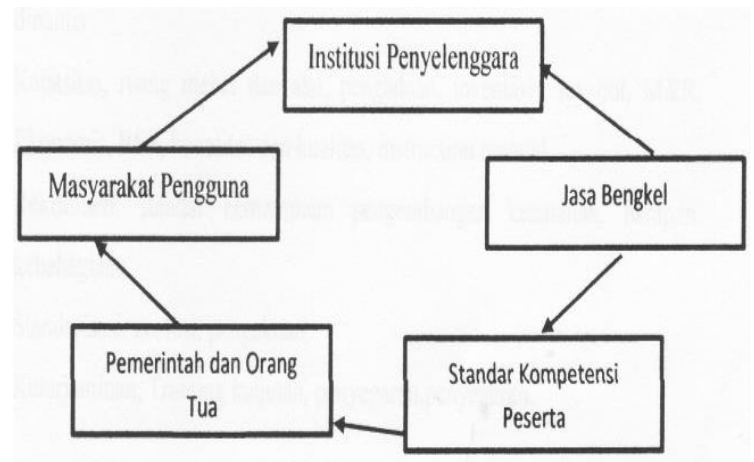

Gambar 1. Manajemen bengkel Sebagai Proses Sirkuler

\section{Perencanaan Bengkel}

Bengkel sebagai kegiatan akademik (ditinjau dari segi pelaksanaannya) dan kegiatan profesional (ditinjau dari segi profesinya), maka pola pendekatan nya harus jelas, karena tidak hanya bersifat Transfer of knowledge tetapi lebih besar pada Transfer of skill, maka pendekatan yang cocok adalah berdasar kompetensi yang lazim disebut CBT (Competency Base Training) atau (Competency Base Training) atau Pelatihan yang berbasis pada kompetensi Untuk langkah-langkah strategis perencanaan bengkel harus memperhatikan hal-hal berikut:

a. Kebutuhan/tuntutan pasar (demand driven)

b. Standar kompetensi yang harus dicapai

c. Komponen pendukung pencapaian standar kompetensi, antara lain :

- Tuntutan pasar

- Penetapan Standar Kompetensi

d. Komponen Pendukung, antara lain :
- Manajemen Input

- Standarisasi bahan Ajar

- Fasilitas Instruktur

e. Pengujian/ Sertifikasi Out Put

- Komunikasl, Aksebtabilitas, Oportunity, Renovasi, Inovasi, Partnership, Iltbang

- Konsekwen, reliabel, optimis, akurat, dinamls

- Marketing, selektlf, kesehatan, manusiawi

- Ekonomls, BEP, kuantltas dan kualltas Instruction manual

- Rekrutmen standar, kemampuan, pengembangan, keamanan, harapan

- Standarisasi, profesi, pengakuan

- Keterjaminan training lanjutan

Pengelolaan Bengkel cakupannya cukup luas mulai dari masalah yang sifatnya rutin dan detail contoh keberslhan ketertiban keselamatan kerja, mekanisme kerja, tanggung 
jawab sampai pada masalah penting dan strategis misal pengadaan fasilitas dan pengembangan fasilitas.

\section{Pengelolaan fasilitas dapat dibagi, antara lain :}

- Ruang

- Paralatan

- Berpedoman kepada perencanaan pekerjaan bengkel

- Pemanfaatan ruangan semaksimal mungkm

- Pengaturan lay out (dengan memprhatlkan faktor efektifitas keselamatan dan keamanan kerja, penggolongan pekerjaan yang sejenis

- Udara, Penerangan

- Llmbah

\section{Pengelolaan fasilitas Peralatan}

Informasl tentang kebutuhan peralatan dapat dlhhat pada brosur Inventaris penggolongan peralatan (alat tangan, alat khusus/SST alat ukur, alat-alat bertenaga (power tools).

\section{Pengelolaan Teach Ware (Teaching Aid dan Trainer)}

Dibuat/diadakan untuk mencapai kompetensi mempercepat/mempermudah pembelajaran. Oleh karenanya, seorang guru supaya selalu memikirkan untuk menciptakan alat bantu megajar (Teaching Aid) agar siswa lebih mudah/cepat mengerti.

Sedangkan Trainer adalah sarana latihan, diusahakan adalah benda asli yang dimodifikasi sedemikian rupa sehingga siap untuk dijadikan sarana latihan. Teaching Aid dan Trainer tersebut sebaiknya diberi nomor, bisa dalam bentuk nomor produksi dan tercantum dalam bahan ajar (job sheet).

\section{Pengembangan Bengkel Diklat}

Pengembangan bengkel harus selalu mendapat perhatian agar bengkel selalu berkembang secara dinamis. Pengembangan dapat berwujud:

- Pengembangan sistem

- Pengembangan fasilitas

- Pengembangan karena tuntutan kompetensi (pengembangan program)

\section{Pengembangan system}

Pengembangan sistem ini dapat dianikan sebagai usaha pengembangan intemal bengkel secara terus menerus, sehingga tetap dapat memenuhi tuntutan dinamika bengkel. Contoh:

- Tata tertib/Peraturan Bengkel

- Kebersihan, sampah, limbah, lay out

- Inovasi, renovasi, promosi, pameran

- SDM

- Keria proyek (bisa metode), dll.
Pengembangan fasilitas harus dilakukan terus/secara periodic (misal:Rencana tahunan) yang didasarkan dan analisa kebutuhan, bisa berupa:

- Mengganti alat yang rusak

- Melengkapi alat yang kurang, baik, baik jumlah maupun jenisnya

- Pembelian alat-alat bam (misalnya : hasil inovasi program)

\section{Pengembangan Program}

Menyadari akan teori life cycle produc, suatu usaha yang ingin tetap berkelanjutan maka harus membuat pengembangan/menciptakan program baru.

Sudah barang tentu pengembangan ini berkaitan dengan:

- Visi dan misi

- Kesiapan SDM

- Dana

- Fasilitas

- Waktu

- Perencanaan desiminasi (kapan dikembangkan dan kapan disosialisasikan)

\section{Tugas Manajemen Bengkel}

Tugas Manajemen Bengkel Lakukan Survey ke Bengkel tentang:

- Latar belakang berdirinya bengkel, meliputi : alasan berdirinya, modal awal bengkel, tenaga kerja awal, penetapan lokasi, visi dan misi bila ada.

- Kondisi saat ini, meliputi: perkembangan omzet, perkembangan tenaga kerja, perkembangan luasan bengkel (termasuk kemungkinan membuka cabang)

- Pengelolaan: kebersihan, keteniban, keselamatan kexja, mekanisme kerja,

- Tanggung jawab, pengadaan fasilitas, pengembangan fasilitas,

- Beberapa kendala/persoalan yang muncul dan upaya jalan keluamya

- Struktur organisasi

\section{GAMBARAN IPTEK YANG AKAN DITRANSFER KEPADA} MITRA

Gambaran Iptek yang akan ditransfer kepada mitra adalah:

a. Manajemen usaha meliputi perencanaan, produksi, keuartan dan pemasaran.

b. Tehnik bongkar pasang mesin, pemasangan spare part, servis kendaraan dan modifikasi kendaraan dengan menggunakan batuan internet untuk desain

c. Modal

Mitra butuh modal dalam memulia usaha dengan pelatihan ini mitra dapat mendapatkan informasi atau bantuan modal kredit usaha rakyat dengan pinjaman rendah bunga. 


\section{d. Administrasi}

Iptek yang ditawarkan pada mitra adalah pelatihan manajemen adaministrasi dan pembukuan keuangan.

\section{KESIMPULAN DAN SARAN \\ KESIMPULAN}

Dari kegiatan pengabdian Iptek bagi Masyarakat dengan judul Pelatihan Keriwausahaan Bengkel bagi Siswa di SMK Karsa Mulya, dapat diambil beberapa kesimpulan yaitu sebagai berikut :

1. Pelatihan kewirausahaan bengkel bagi SMK khususnya jurusan mesin dan otomotif sangat baik untuk dilakukan untuk mempersiapkan mereka para siswa memasuki dunia kerja setelah menyelesaikan pendidikan.

\section{Saran-saran}

1. Agar pihak SMK semakin sering membuka diri untuk bekerjasama dengan pihak lain yang bisa memberikan kontribusi pengetahuan bagi Siswa

2. Agar adanya kerjasama antara Universitas Palangka Raya khusunya jurusan Pendidikan Teknik Mesin dengan SMK Karsa Mulya dalam pengembangan ilmu otomotif dan perbengkelan.

\section{DAFTAR PUSTAKA}

[1]. Ardianto, Elvianaro. 2012. Metode Penelitian Untuk Public Relations, Kualitatif dan Kuantitatif Jakarta. Simbios Rekatama Media

[2]. Holowenko, A.R. Dinamika Permesinan. Diterjemahkan oleh Ir. Cendy Prapto. Jakarta: Erlangga, 1985

[3]. Hanson, Ward. 2000. Pemasaran Internet Qpriczples of Internet Markating). Jakarta. Salemba Empat.

[4]. Popov, E. P. Mekanika Teknik, edisi ke II. Diterjemahkan oleh Zainul Astanam Tanisan, M.Sc, Jakarta: Erlangga, 1983

[5]. Puntoadi. Danis. 201 1. Menczptakan Penjualan Melalui Sosial Media. Jakarta. PT. Alex Media Komputindo

[6]. Holowenko, A.R. Dinamika Permesinan. Diterjemahkan oleh Ir. Cendy Prapto. Jakarta: Erlangga, 1985

[7]. Sutantra, Nyoman. Teknologi Otomitf Teori dan Aplikasinya. Surabaya: Guna Widya, 2001

[8]. Sularso and Suga, Kiyokatsu. Dasar Perancangan dan Pemilihan Elemen Mesin. Jakarta 1 Pradnya Palamitha, 1997

[9]. http://marketing.co.id/blog/2016/6/05/transaksi juabeli-melalui-media-sosial. 